\title{
TU/e EmonOWEN

\section{Cholesteric flakes in motion driven by the elastic force from nematic liquid crystals}

\section{Citation for published version (APA):}

Liu, W., Zhou, Y., Liu, S., Shao, W., Broer, D. J., Zhou, G., Yuan, D., \& Liu, D. (2019). Cholesteric flakes in motion driven by the elastic force from nematic liquid crystals. ACS Applied Materials and Interfaces, 11(43), 40916-40922. https://doi.org/10.1021/acsami.9b14650

DOI:

10.1021/acsami.9b14650

Document status and date:

Published: 30/10/2019

\section{Document Version:}

Publisher's PDF, also known as Version of Record (includes final page, issue and volume numbers)

\section{Please check the document version of this publication:}

- A submitted manuscript is the version of the article upon submission and before peer-review. There can be important differences between the submitted version and the official published version of record. People interested in the research are advised to contact the author for the final version of the publication, or visit the $\mathrm{DOI}$ to the publisher's website.

- The final author version and the galley proof are versions of the publication after peer review.

- The final published version features the final layout of the paper including the volume, issue and page numbers.

Link to publication

\section{General rights}

Copyright and moral rights for the publications made accessible in the public portal are retained by the authors and/or other copyright owners and it is a condition of accessing publications that users recognise and abide by the legal requirements associated with these rights.

- Users may download and print one copy of any publication from the public portal for the purpose of private study or research.

- You may not further distribute the material or use it for any profit-making activity or commercial gain

- You may freely distribute the URL identifying the publication in the public portal.

If the publication is distributed under the terms of Article 25fa of the Dutch Copyright Act, indicated by the "Taverne" license above, please follow below link for the End User Agreement:

www.tue.nl/taverne

Take down policy

If you believe that this document breaches copyright please contact us at:

openaccess@tue.nl

providing details and we will investigate your claim. 


\title{
Cholesteric Flakes in Motion Driven by the Elastic Force from Nematic Liquid Crystals
}

\author{
Wei Liu, ${ }^{\dagger, \ddagger}$ Yong Zhou, ${ }^{\dagger,}$ Sunqian Liu, ${ }^{\dagger, \ddagger}$ Wan Shao, ${ }^{\ddagger}$ Dirk J. Broer, ${ }^{\dagger, \S}$ Guofu Zhou, ${ }^{\dagger, \ddagger}$ Dong Yuan, ${ }^{*}, \dagger, \ddagger$ \\ and Danqing Liu*, ${ }^{\dagger}, \S(0)$
}

\begin{abstract}
${ }^{\dagger}$ SCNU-TUE Joint Lab of Device Integrated Responsive Materials (DIRM), National Center for International Research on Green Optoelectronics, Guangzhou Higher Education Mega Center, South China Normal University, No 378, West Waihuan Road, Guangzhou 510006, China

${ }^{\ddagger}$ Guangdong Provincial Key Laboratory of Optical Information Materials and Technology \& Institute of Electronic Paper Displays, South China Academy of Advanced Optoelectronics, South China Normal University, Guangzhou 510006, P. R. China

${ }^{\S}$ Stimuli-responsive Functional Materials and Devices (SFD), Eindhoven University of Technology, Groene Loper 5, Eindhoven 5612 AE, The Netherlands
\end{abstract}

Supporting Information

\begin{abstract}
The paper presents a methodology to control the motion and orientation of suspended reflective cholesteric flakes in a nematic liquid crystal (LC) matrix. The flakes exhibit a dielectric anisotropy which controls their alignment with their in-plane axes parallel to an external electrical dc field. The elastic forces imposed by the LC host affect the switching behavior of the flakes and take care of the realignment to the planar state as soon as the dc field is switched off. When the LC host has a positive dielectric anisotropy, the switching voltage of the flakes is reduced by a factor of 2 in comparison with a LC host with negative dielectric anisotropy or in comparison with an isotropic host. We discovered that the LC host further regulates the back relaxation of cholesteric to return to the planar state upon retrieving the electric field. Whereas, in the isotropic fluid, flakes do not exhibit a preferred orientation when relaxed. Based on this newly proposed principle, we demonstrated its application as an optical switch for smart windows. Depending on the pitch of the cholesteric helix of the flakes, the light of a preset

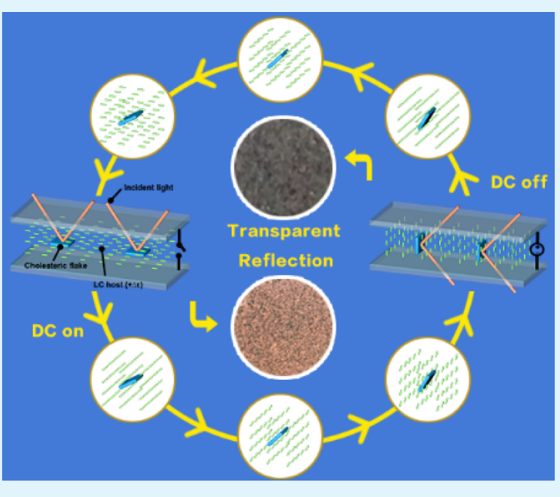
wavelength is reflected. Upon application of an electric field, the embedded flakes rotate their planes perpendicular to the substrate and consequently the incident light becomes fully transmitted without reflection or scattering of light.
\end{abstract}

KEYWORDS: liquid crystals, nematic elasticity, electric-driven, cholesteric flakes, optical switches

\section{INTRODUCTION}

Windows play a key role in modern building design, and often they take more than $80 \%$ of the area of the building facade. ${ }^{1,2}$ Where the exterior of traditional buildings predominantly consist of traditional, nontransparent construction materials, new building designs come with a more open view to the outside world and windows merged into buildings as a luxury desire from humans enabling the entrance of daylight and a visual connection with the outside world. ${ }^{3}$ However, this comes with a price as the influx of light and heat and privacy is less controlled. With the rapid advances in science and technologies, new functional/responsive devices are emerging in our society. ${ }^{4}$ In this context, smart windows add to the comfort of living by adjustable privacy and improved energy management. ${ }^{5,6}$ Currently, a few smart window principles are available based on the electrically controlled light scattering of blend polymers and liquid crystals (LCs). In polymerdispersed liquid crystals (PDLCs), the scattering is based on a refractive index mismatch between a polymer and embedded phase-separated LC droplets. The index mismatch is reduced by the alignment of the LC in an electric field which matches the ordinary refractive index of the LC with the refractive index of the polymer..$^{7-10}$ In polymer-stabilized liquid crystals, the scattering originates from a combination of polydomain formation of the LC, inducing multiple refractive index transitions, and a refractive index mismatch between the ordinary index of the LC and the extraordinary index of the LC polymer, or vice versa, by switching on the electric field. ${ }^{11-14}$ In yet another design based on a cholesteric LC, scattering is modulated by switching between a planar aligned state and a focal conic state induced by a voltage pulse at a specific frequency. ${ }^{15-18}$ Also, electro-hydrodynamic instabilities were explored for smart windows in which scattering stems from the chaotic turbulence created in LCs when charge carriers oscillate under an applied ac electric field. ${ }^{19-21}$ A common disadvantage of all these approaches is that in their scattering

Received: August 16, 2019

Accepted: October 10, 2019

Published: October 10, 2019 
Scheme 1. Materials Used for PCLC Flakes Compositions ${ }^{a}$

1<smiles>C=CC(=O)OCCCOc1ccc(C(=O)Oc2ccc(OC(=O)c3ccc(OCCCOC(=O)C=C)cc3)c(C)c2)cc1</smiles>

2<smiles>COC(O)CCCCCCOC1CCC(C(O)C(O)OC2CCC(OC)CC2)CC1</smiles>

3

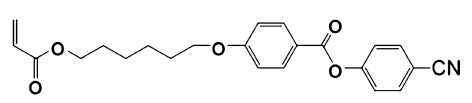

4

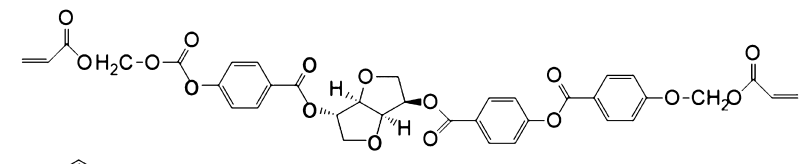

5

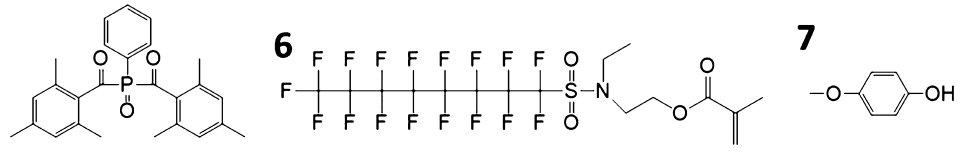

${ }^{a}$ Materials 1-3 are liquid crystal monomers. 4 is the chiral dopant. 5 is the photoinitiator. 6 is the surfactant. 7 is the inhibitor.

state they block only a small part of the incoming light as most of the light scatters in the forwarding direction. This provides privacy but cannot exclude light and heat from entering the interior. Alternatively, both guest-host LC windows and electrochromic windows are available which switch from a transparent to an absorbing state. ${ }^{22-24}$ These window types operate at a relatively low voltage but have the disadvantage that in their absorbing state they heat up under the exposure to sunlight and are intrinsically sensitive for photo-degradation.

In this work, we propose an electro-optical switch that modulates light transmission by reflection at rotatable cholesteric flakes that rotate under an applied external field. The use of dielectric force to rotate flakes that are suspended in an isotropic liquid is known. ${ }^{25-27}$ Our innovation here is that we suspend cholesteric flakes in an LC host and employ the elastic force from the LC host to regulate the motion of flakes both in the switching on ${ }^{28}$ and the switching off states. With the rotating cholesteric flakes, we create the possibility to reflect light as a specific wavelength depending on the pitch of the cholesteric pitch.

\section{RESULTS AND DISCUSSION}

We prepared cholesteric flakes of $60 \times 60 \times 10 \mu \mathrm{m}$ by photopolymerization of a monomer mixture with the cholesteric (chiral-nematic) order in a silicone mold. The monomer mixture consists of a homogeneous blend of liquidcrystal mono and diacrylates, an acrylate chiral dopant, and the photoinitiator. Details are given in the Experimental Section and in Supporting Information Figure S1. The mesogenic molecular rods on average describe a rotation along their helix axes orthogonal to the flake surface. The reflection stems from the Bragg-type interference at the periodic refractive indices of the quasicholesteric layers. ${ }^{29,30}$ The flakes reflect circularly polarized light at a wavelength equal to the helical pitch multiplied by the average refractive index of the cholesteric medium. The cholesteric pitch can be accurately adjusted by the concentration of a reactive chiral dopant added to the LC monomer mixture prior to its polymerization. In our specific experiments, the chiral monomeric additive gives a helix with a right-handed rotation and consequently, the flakes reflect righthanded circularly polarized light (Experimental Section, Scheme 1, molecule 4).

In the first experiment, we suspended the cholesteric flakes in a nematic LC host mixture with negative dielectric anisotropy $(\Delta \varepsilon=-8.3)$, further referred to as the negative LC host. The flake-LC suspension is brought in a cell constructed of two glass plates provided with transparent indium tin oxide (ITO) electrodes and rubbed poly(vinyl alcohol) layers providing a planar alignment of the LC host. The two glass plates are at a distance of $150 \mu \mathrm{m}$ as controlled by glass spacers. Initially, at zero voltage, the nematic host LC is uniaxial and planar aligned parallel to the glass plate as observed by its birefringence color under the crossed polarizers. The suspended cholesteric flakes align themselves with their $x-y$ planes along with the LC director as governed by the interfacial potential from the glass surfaces (Figure la,c). ${ }^{31,32}$ Each individual flake has the axes of the cholesteric
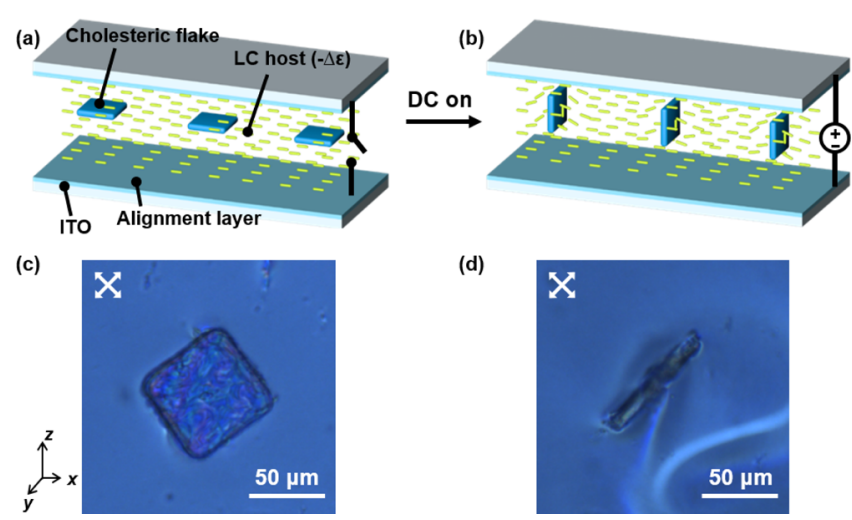

(d)

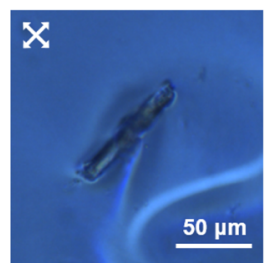

Figure 1. Motion of cholesteric flakes when they are suspended in a negative LC host. Schematic representation of the position of cholesteric flakes with respect to the LC host alignment. (a) LC host is planar aligned at the voltage-off state, and (b) LC host keeps its initial orientation under the applied dc voltage. Optical microscopic images under the cross-polarizers show (c) cholesteric flake in a planar aligned LC host at zero voltage, and (d) flake rotates $90^{\circ}$ at a dc voltage of $66.7 \mathrm{mV} / \mu \mathrm{m}$ while the LC is still planar oriented.

helices along the transmission axis of the incoming light and reflects light. Typically, the pitch of the cholesteric helix of the flakes is $400 \mathrm{~nm}$ and reflects light at the wavelength of $640 \mathrm{~nm}$. When a dc field (data on applying the ac field is given in Figure S2, Supporting Information) is applied across the cell thickness, the LC host keeps the original alignment due to its negative dielectric anisotropy, the planar alignment is also indicated by its birefringence color observed between two 
crossed polarizers. Importantly, despite the host, LC keeps its planar alignment while the cholesteric flakes rotate with its $x-y$ plane parallel to the substrate normal at the voltage of $66.7 \mathrm{mV}$ $\mu \mathrm{m}^{-1}$ (Figure $1 \mathrm{~b}, \mathrm{~d}$, Movie SI). This motion is solely governed by the dielectric force acting on the flakes which requires a voltage at $66.7 \mathrm{mV} \mu \mathrm{m}^{-1}$.

Next, we exchange the LC host for the one with a positive dielectric anisotropy $(\Delta \varepsilon=12.9)$, further referred to as the positive LC host. Initially, this LC is uniaxial oriented and the cholesteric flakes are positioned with an $x-y$ plane parallel to the substrate surface as shown in Figure 2a,c. Upon the
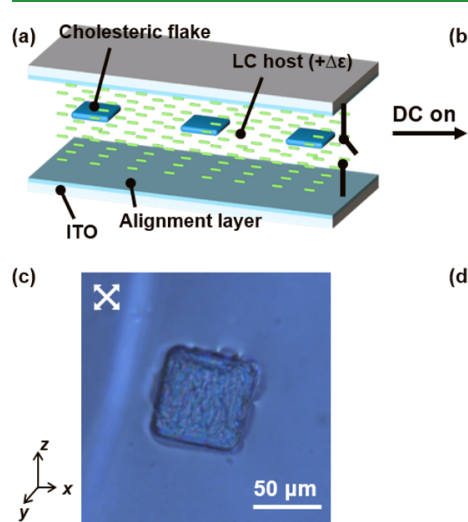

(d)

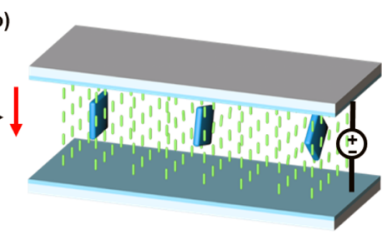

Figure 2. Motion of cholesteric flakes when they are suspended in the positive LC host. Schematic representation of cholesteric flakes when the LC host is (a) uniaxial aligned at zero voltage and (b) homeotropic aligned under an applied dc voltage. Optical microscopic images under cross-polarizers show (c) cholesteric flake in a planaraligned LC host in the absence of an electrical field voltage, and (d) same flake tilts following the alignment of homeotropically aligned LC host under a dc voltage of $33 \mathrm{mV} / \mu \mathrm{m}$. application of a direct electric field (dc) at $33 \mathrm{mV} \mu \mathrm{m}^{-1}$, across the cell, the initially planar-oriented positive LC host tilts $90^{\circ}$ toward the socalled homeotropic alignment in $15 \mathrm{~s}$. While the embedded cholesteric flakes slowly follow the nematic host in $28 \mathrm{~s}$ by rotating their planes perpendicular to the substrate thereby inducing topological defects (polydomain) in the LC host as shown in Figure $2 \mathrm{~b}$,d. In a reference experiment, pure LC under the same conditions realigns from its initial planar to homeotropic configuration spontaneously in 13 s (Figure S3, Supporting Information). As the same in the negative LC host, the flakes are under the action of the dielectric forces because of its dielectric anisotropy. However, now, contrary to the negative LC host, the positive LC host provides additional elastic forces to rotate the flakes and thus requires a much lower voltage $(33 \mathrm{mV} / \mu \mathrm{m}){ }^{33-35}$

For most applications, cholesteric flakes suspended in the positive LC is more interesting than the negative one as it provides a lower driven voltage. For this reason, we investigated the flakes motion in the positive LC host in more detail. As shown in Figure $3 \mathrm{a}, \mathrm{b}$, by increasing the dielectric anisotropy of the LC host (Table S1, Supporting Information) or the applied electric field, the flakes rotate faster as a larger force is exerted on the flakes. We also observed that at a relatively high field strength a further increase of the LC dielectric anisotropy does not have a measurable effect on the rotation time of the flakes which is dominated by the fluid dynamic drag from the LC host. In general, the fluid drag can be reduced by lowering the fluid viscosity. As shown in Figure $3 \mathrm{c}, \mathrm{d}$, we elevate the environmental temperature, LC host becomes less viscous and consequently the responding time increase. This effect is also observed in the nonLC isotropic host. ${ }^{36}$ The influence of the fluid viscosity is further verified by replacing the LC fluid with an isotropic liquid (Figure S4, Table S2, Supporting Information).
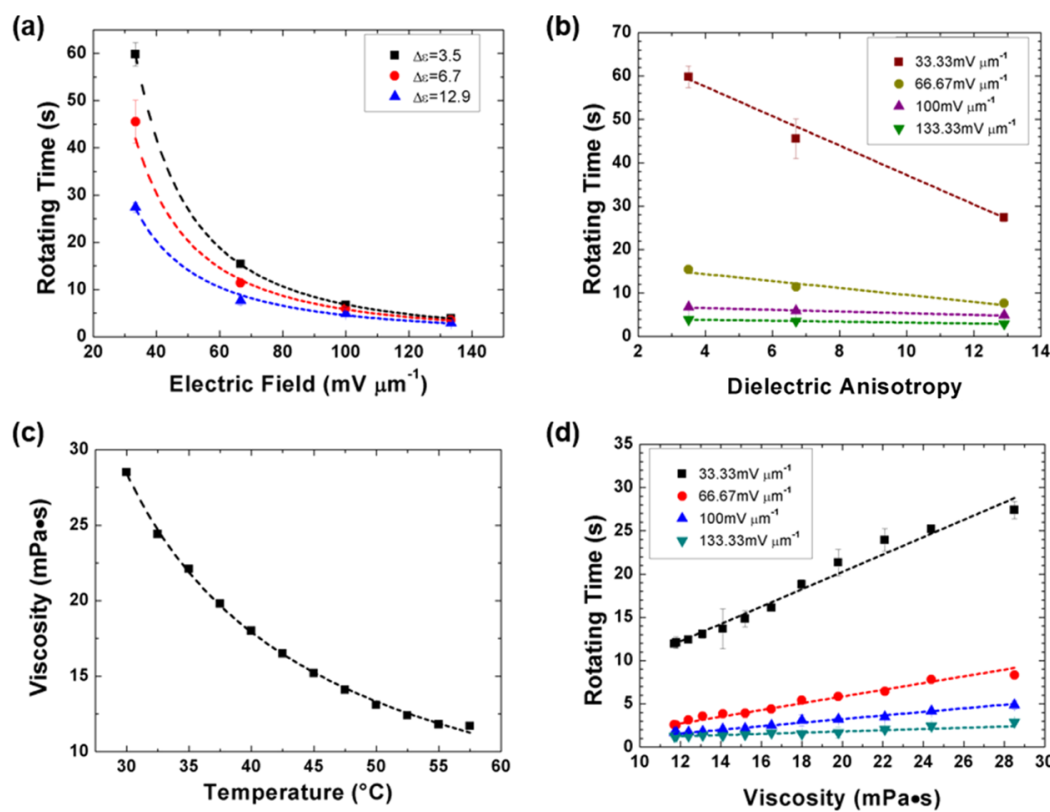

(d)

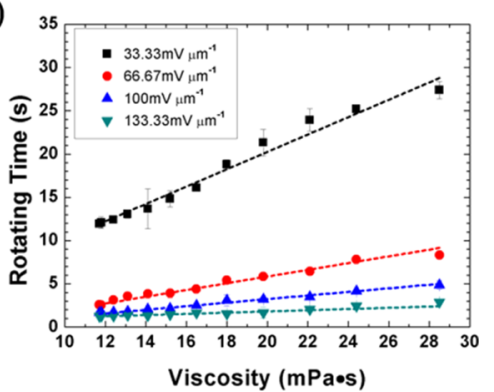

Figure 3. Details of the flakes' rotation time. (a) Flakes' rotation time reduces with the increasing electric field strength and the dielectric anisotropy. The environmental temperature is $30^{\circ} \mathrm{C}$. (b) Influence of LC dielectric anisotropy on measured rotation time of flakes at various field strengths. Temperature is kept at $30^{\circ} \mathrm{C}$. (c) Decrease of the shear viscosity of LC host measured by a couette viscometer with the increasing temperature. (d) Reduction of the flakes' rotation time in a low viscous LC host by increasing the environmental temperature. The dielectric anisotropy is 12.9 . 
Upon switching off the applied electric field, the positive LC host transfers from the perpendicular state to planar orientation while the negative LC host remains its planar alignment. In both cases, the planar orientation (Figure $4 \mathrm{a}$ ) is

(a)
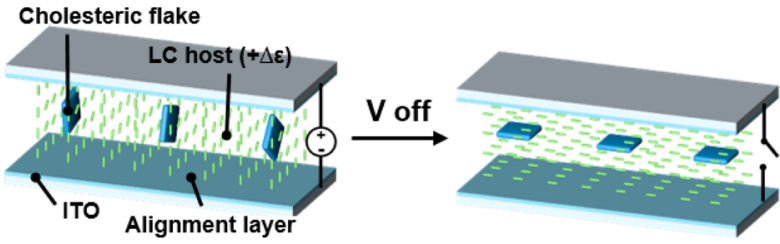

(b)
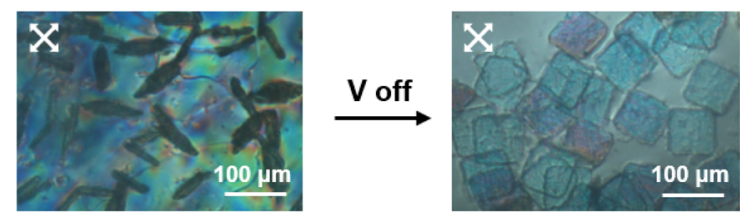

(c)

$$
\text { Cholesteric flake }
$$

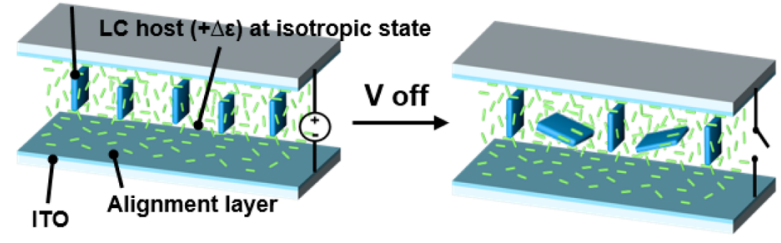

(d)
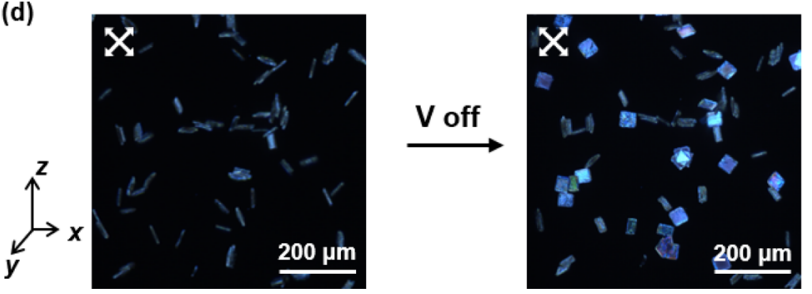

Figure 4. Relaxation process after turning off the applied electric field. (a) Schematic representation illustrates upon stopping the dc field, the orientation of flakes in the positive LC host at the nematic state. (b) Optical microscopic images of flakes distributed in the nematic LC positive host. Flake distribution in the LC negative host is presented in Figure S5, Supporting Information. (c) Schematic representation shows the orientation of the flakes in the positive LC host at its isotropic state and (d) corresponding optical microscopic images.

governed by the surface anchoring force from the alignment layer. ${ }^{12}$ Figure $4 \mathrm{~b}$ shows that the elastic force of the positive LC host tilts the flakes with their $x-y$ plane from normal to parallel to the substrate in $30 \mathrm{~s}$. To investigate the influence of the LC host on the relaxation of the flakes, we designed a reference experiment in which the elastic force is excluded. For this purpose, we elevated the temperature of the LC host above its nematic-isotropic transition temperature. When the electric field is switched on the cholesteric flakes align along the field lines. The optical microscopic image shows black between cross-polarizers that remain black upon rotation of the polarizers indicating the isotropic state. By removing the $\mathrm{dc}$ field, the flakes slowly relax $(60 \mathrm{~s})$ by taking a random orientation with their $x-y$ plane perpendicular, parallel, or tilted due to the absence of the elastic force from the LC host. See Figure 4c,d. Obviously, the absence of elastic forces in the isotropic host did not bring them into a preferred orientation.

With the full control over the flakes motion, we demonstrate that the proposed method can be used as an optical switch for smart window applications. As shown in Figure 5a, 69400 flakes $/ \mathrm{cm}^{2}$ with a dimension of $40 \times 40 \times 4.5 \mu \mathrm{m}(L \times W \times$ $H)$ are distributed in the positive LC host $(\Delta \varepsilon=12.9)$. The amount of the flakes is chosen for relatively low switching voltage. The cell thickness is $70 \mu \mathrm{m}$. Without applying the external electric field, the flakes align with the axes of the cholesteric helix along the transmission axis of the incoming light and reflect the light at the wavelength of $640 \mathrm{~nm}$. Because of the cholesteric nature, only right-circularly polarized light is reflected while left circularly polarized light passes through (Figure 5b). Currently, most LC-based smart windows utilize light scattering for the optical opaque state. However, in this scattering closed state, only a limited part of the light is blocked whereas most of the light is scattered in the forward direction. We also measured the light flux that passes through the windows with the set-up presented in Figure 5c. We used an integrating sphere in contact with the sample to collect the forward scattered light at the voltage off state. The measured results are presented in Figure $5 \mathrm{~d}$. At the optically opaque state at zero voltage, a scattering-based polymer-dispersed liquid crystal (PDLC) system (Experimental Section) window transmits close to $90 \%$ of the light energy and only $10 \%$ of the light is blocked because of backward scattering. In comparison, our proposed approach prevents more light from passing through by reflecting almost $50 \%$ of the light as cholesteric flakes reflects one handedness of circularly polarized light. By applying an electric field of $15 \mathrm{~V}$ across the cell, both principles exhibit high-light transparency. The still somewhat lower transmittance of the flake system is most likely due to some scattering because of a mismatch between the ordinary refractive index of the host LC and the in-plane indices of the flakes, which can be further improved by material optimization.

To study the energy consumption in our device, we measured the current consumed in the circuit. The equivalent electric circuit used for the measurement is given in Figure S6, Supporting Information. Our system shows a typical linear $V-I$ relationship, the resistant is $3.84 \mathrm{M} \Omega$. For comparison, the measured leakage current in the PDLC window increases exponentially by increasing the applied voltage which is explained by the presence of ionic contamination inside the polymer which is polarized by the dc electric field. Also in our proposed system, ionic contaminations are considered to be responsible for leakage current. At a typical voltage of $15 \mathrm{~V}$ applied to rotate the flakes, the electric power consumed for switching on the window is calculated as $5.865 \times 10^{-5} \mathrm{~W}$ (Formula S1, Supporting Information) which is comparable to the PDLC system.

\section{CONCLUSIONS}

In conclusion, we have presented an approach to modulate the orientation of liquid suspended flakes. The underlying principle is based on switching the orientation of the cholesteric flakes by their anisotropic dielectric interaction with an external field. This can be further stimulated by the positive contribution of elastic forces when the flakes are embedded in a positive LC host. The use of the elastic force not only substantially reduces the switching voltage by the factor of 2 but also largely supports and regulates the flakes' relaxation process upon retrieving the electric field, such that the $x-y$ plane of flakes are suppressed to be parallel to the LC director. This control makes it possible for the smart window applications with the advantages of preventing light/heat energy passing through the windows. We have demonstrated 
(a)

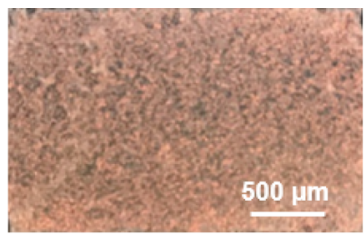

(b)

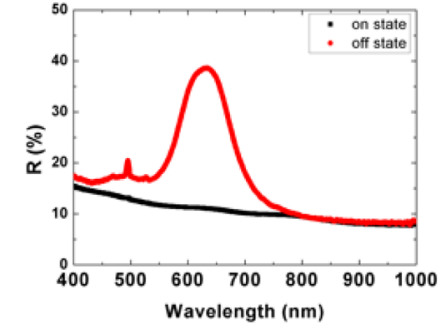

(d)

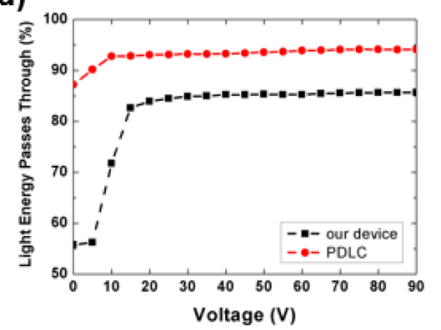

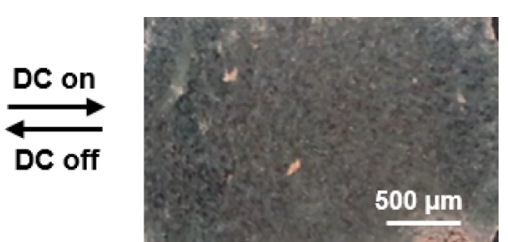

(c)

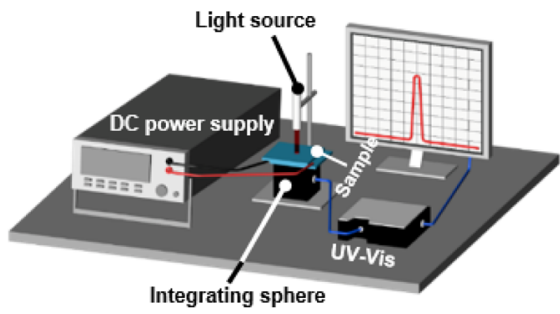

(e)

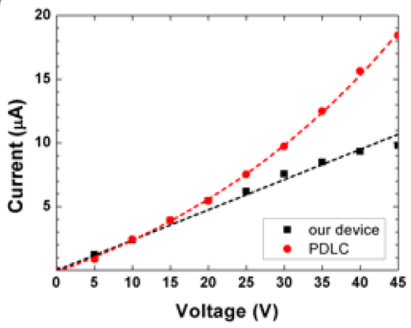

Figure 5. Smart window application. (a) "Smart" window is switched from light blocking to the transparent state by controlling the orientation of cholesteric flakes. The sample is placed against the black background (b) measured light transmittance when the voltage is switched on and off. (c) Schematic representation illustrating the setup used for measuring the light energy passes through the window. (d) Measurements show the proposed method blocks more light energy compared with PDLC system. The light wavelength used for the measurement is 650-660 nm. (e) Current generated in the window when voltage is applied.

approximately $50 \%$ of the reflection which can be brought to higher values by a blend of flakes that reflect both handednesses of circularly polarized light, or stacking of flakes with the same handiness with intermediate LC that provides a half wave retardation function. We can also broaden the reflection spectrum by using flakes with a pitch gradient in the cholesteric helix. We anticipate this technology can be used for heat regulation and a variety of optical switches.

\section{EXPERIMENTAL SECTION}

Materials. An overview of the materials used for PCLC flakes fabrication is provided in Scheme 1 . The flakes are produced by the photo-copolymerization of four liquid crystalline monomers. Monomers 1 to 4 were obtained from $\mathrm{HCCH}$ (Jiangsu, China). Photoinitiator 5 was obtained from HEOWNS (Tianjin, China). Typically, thin PCLC flakes were fabricated from a mixture containing 21 wt \% monomer 1, $41.5 \mathrm{wt} \%$ monomer 2, 31 wt \% monomer 3, 4 wt \% monomer 4, and 2 wt \% photoinitiator 5. Surfactant 6 (2-(Nethylperfluorooctanesulfonamido)ethyl methacrylate, 0.5 wt \%), Reagent Biotechnology Co., Ltd. (Shenzhen, China), was used to control the LC alignment at the air interface and to avoid de-wetting during the coating process. Inhibitor 7 (hydroquinone, $200 \mathrm{ppm}$ ) which was used to avoid premature polymerization was purchased from HEOWNS (Tianjin, China). In order to adjust the selective reflection wavelength, we varied the concentration of chiral dopant monomer 4. The constituents were mixed by dissolving in dichloromethane which was evaporated subsequently. DSC results show that the mixture has the chiral-nematic phase in the temperature range between 46 and $55{ }^{\circ} \mathrm{C}$. At higher temperatures it becomes isotropic.

In this study, we used LC hosts with either positive or negative dielectric anisotropy. The LC host with positive dielectric anisotropic is E7 mixture, CDZSL010 mixture, and CDZSL013 mixture. The E7 mixture was purchased from Jiangsu Creative Electronic Chemicals, CDZSL010 mixture and CDZSL013 mixture were purchased from Nanjing Murun new material technology Co., Ltd. (Jiangsu, China). In the main text, the study on the motion of the flakes we selected LC mixture E7 as a positive host. Negative LC host is HNG30400-200 which was purchased from $\mathrm{HCCH}$. (Jiangsu, China). We also compare a number of isotropic hosts with different viscosity, all the isotropic hosts were purchased from GBS Technology (Guangzhou, China).

Sample Preparation. Fabrication of the cholesteric flakes is detailed in Figure S1, Supporting Information. The cell for study the rotation of the flakes was made of two ITO-coated glass substrate with electrodes on both sides. An alignment layer was coated on top of the ITO electrode. Poly(vinyl alcohol) (PVA, molecular weight 9000-10 000, Aldrich Chemistry, Germany) aqueous solution was used to obtain the planar alignment of the LC host. The PVA was spin-coated on cleaned ITO glass, followed by baking, and rubbing with a polyester cloth. The thickness of the cell for testing was controlled with spacers with $150 \mu \mathrm{m}$ diameter mixed in UV glue, which forms the frame of the device after UV curing. The flakes and LC host are mixed by ultrasonic vibration for half an hour to get sufficient and even mixing. The obtained suspension was filled into the cell by capillary force after which the cell is closed with glue. Another cell for smart window demonstration was made with $70 \mu \mathrm{m}$ diameter mixed in UV glue. The glue mixture was put on the corner of the bottom ITO substrate, one drop of flakes and LC host mixture was put on the center, and another ITO substrate was covered upon them. Finally, the device was made after UV curing and encapsulation.

Sample Characterization. The samples were driven by a dc power source (Keithley 2400) which generates voltages from 0 to 200 $\mathrm{V}$. The status of the flakes and host LC in the devices at different states were checked by polarized microscopy (POM; Leica DM2700P). The rotation process of the flakes was captured by a CCD camera (Infinity 1-3C) with 24-bit resolution, and then the 
rotating time of the flakes was obtained from the video. The operating temperature of the devices was controlled by a thermal stage (Linkam THMS600). The reflection spectrum of the flakes was measured by a spectrometer (Ocean Optics HR2000+). A light source (Knorvay N76) was used to provide $650-660 \mathrm{~nm}$ light. The power of transmitted light was measured by a spectrometer (Ocean Optics HR2000+). Leaking current of the device was tested by a picoammeter (Keithley 6487). The PDLC sample used for comparison was bought from Zhuhai Singyes New Materials Technology Co. Ltd. (Zhuhai, China). The viscosity of host LC was measured by a Rheometer (Haake MARS III).

\section{ASSOCIATED CONTENT}

\section{S Supporting Information}

The Supporting Information is available free of charge on the ACS Publications website at DOI: 10.1021/acsami.9b14650.

Schematic diagram of flakes fabrication process, influence of $\mathrm{AC}$ field on the motion of the flakes, realignment time of pure LC (E7) under different electric field strength, parameters of the positive LC host with different dielectric anisotropy, parameters of the isotropic host, rotating time of flakes in the isotropic liquid with different viscosity, relaxation process of flakes in the negative LC host, and equivalent circuit diagram (PDF)

Rotation process of the flakes (MP4)

\section{AUTHOR INFORMATION}

\section{Corresponding Authors}

*E-mail: yuandong@scnu.edu.cn (D.Y.).

*E-mail: d.liu1@tue.nl (D.L.).

\section{ORCID}

Guofu Zhou: 0000-0003-1101-1947

Danqing Liu: 0000-0001-8830-0443

Notes

The authors declare no competing financial interest.

\section{ACKNOWLEDGMENTS}

The results presented are part of research programs financed by the National Natural Science Foundation of China (21711530647, 51561135014, U1501244), Science and technology project of Guangdong Province (no. 2018A050501012), Guangdong Innovative Research Team Program (no. 2013C102), European Research Commission under ERC Advanced Grant 66999 (VIBRATE) and NWO VENI grant 15135, Guangdong Provincial Key Laboratory of Optical Information Materials and Technology (no. 2017B030301007), MOE International Laboratory for Optical Information Technologies, South China Academy of Advanced Optoelectronics and the 111 Project.

\section{REFERENCES}

(1) Ramírez, E.; Pujols, W. C.; Casares, F. J.; Ramírez-Faz, J.; LópezLuque, R. Development of a Suitable Synthetic Projection to Simultaneously Study Solar Exposure and Natural Lighting in Building Windows. Energy Build. 2013, 65, 391-397.

(2) Atkinson, J. W. Window Greenhouse. U.S. Patent 4,038,791A, Aug 2, 1977.

(3) Bains, S. Windows of Opportunity [Smart Windows for Light/ Heat Blocking]. IEE Rev. 2005, 51, 40-43.

(4) Rezaei, S. D.; Shannigrahi, S.; Ramakrishna, S. A Review of Conventional, Advanced, and Smart Glazing Technologies and
Materials for Improving Indoor Environment. Sol. Energy Mater. Sol. Cells 2017, 159, 26-51.

(5) Baetens, R.; Jelle, B. P.; Gustavsen, A. Properties, Requirements and Possibilities of Smart Windows for Dynamic Daylight and Solar Energy Control in Buildings: A State-Of-The-Art Review. Sol. Energy Mater. Sol. Cells 2010, 94, 87-105.

(6) Slooff, L. H.; Bende, E. E.; Burgers, A. R.; Budel, T.; Pravettoni, M.; Kenny, R. P.; Dunlop, E. D.; Büchtemann, A. A Luminescent Solar Concentrator with $7.1 \%$ Power Conversion Efficiency. Phys. Status Solidi RRL 2008, 2, 257-259.

(7) Wang, H.; Wang, L.; Chen, M.; Li, T.; Cao, H.; Yang, D.; Yang, Z.; Yang, H.; Zhu, S. Bistable Polymer-Dispersed Cholesteric Liquid Crystal Thin Film Enabled by a Stepwise Polymerization. RSC Adv. 2015, 5, 58959-58965.

(8) Gao, Y.; Song, P.; Zhang, T.; Yao, W.; Ding, H.; Xiao, J.; Zhu, S.; Cao, H.; Yang, H. Effects of a Triethylamine Catalyst on Curing Time and Electro-Optical Properties of PDLC Films. RSC Adv. 2013, 3, 23533-23538.

(9) Li, W.; Yu, L.; He, W.; Yuan, X.; Zhao, D.; Huang, W.; Cao, H.; Yang, Z.; Yang, H. Effect of a Photopolymerizable Monomer Containing a Hydrogen Bond on Near-Infrared Radiation Transmittance of Nematic Liquid Crystal/Monomers Composites. J. Phys. Chem. C 2008, 112, 13739-13743.

(10) Sun, Y.; Zhang, C.; Cao, H.; Xiao, J.; Ding, H.; Li, F.; Yu, H.; Yang, Z.; Yang, H. Effects of Functionality of Thiol Monomer on Electro-Optical Properties of Polymer-Dispersed Liquid Crystal Films. Liq. Cryst. 2017, 44, 1086-1092.

(11) Moheghi, A.; Nemati, H.; Yang, D.-K. Polarizing Light Waveguide Plate from Polymer Stabilized Liquid Crystals. Opt. Mater. Express 2015, 5, 1217-1223.

(12) Kraig, R. E.; Taylor, P. L.; Ma, R.; Yang, D.-K. Nematic Order in Polymer-Stabilized Liquid Crystals. Phys. Rev. E: Stat. Phys., Plasmas, Fluids, Relat. Interdiscip. Top. 1998, 58, 4594.

(13) Gu, D. F.; Jamieson, A. M.; Chien, L. C. Dynamic Light Scattering Study of Polymer-Stabilized Liquid Crystal Monodomain. Mol. Cryst. Liq. Cryst. Sci. Technol., Sect. A 1996, 287, 295-304.

(14) Yang, D.-K.; Chien, L. C.; Doane, J. W. Cholesteric liquid crystal/polymer dispersion for haze-free light shutters. Appl. Phys. Lett. 1992, 60, 3102-3104.

(15) Ma, J.; Shi, L.; Yang, D.-K. Bistable Polymer Stabilized Cholesteric Texture Light Shutter. Appl. Phys. Express 2010, 3, 021702 .

(16) Yang, D.-K.; West, J. L.; Chien, L. C.; Doane, J. W. Control of Reflectivity and Bistability in Displays Using Cholesteric Liquid Crystals. J. Appl. Phys. 1994, 76, 1331-1333.

(17) Moheghi, A.; Nemati, H.; Li, Y.; Li, Q.; Yang, D.-K. Bistable Salt Doped Cholesteric Liquid Crystals Light Shutter. Opt. Mater. 2016, 52, 219-223.

(18) White, T. J.; Bricker, R. L.; Natarajan, L. V.; Tondiglia, V. P.; Green, L.; Li, Q.; Bunning, T. J. Electrically Switchable, Photoaddressable Cholesteric Liquid Crystal Reflectors. Opt. Express 2010, 18, 173-178.

(19) Zhan, Y.; Schenning, A. P. H. J.; Broer, D. J.; Zhou, G.; Liu, D. Light-Driven Electrohydrodynamic Instabilities in Liquid Crystals. Adv. Funct. Mater. 2018, 28, 1707436.

(20) Serak, S. V.; Hrozhyk, U.; Hwang, J.; Tabiryan, N. V.; Steeves, D.; Kimball, B. R. High Contrast Switching of Transmission due to Electrohydrodynamic Effect in Stacked Thin Systems of Liquid Crystals. Appl. Opt. 2016, 55, 8506-8512.

(21) Zhang, B.; Kitzerow, H. Pattern Formation in a Nematic Liquid Crystal Mixture with Negative Anisotropy of the Electric Conductivity-A Long-Known System with "Inverse" Light Scattering Revisited. J. Phys. Chem. B 2016, 120, 6865-6871.

(22) Taheri, B.; Kosa, T.; Bodnar, V.; Sukhomlinova, L.; Su, L.; Martincic, C.; Chonko, J.; Park, E.-Y. In Guest-Host Liquid Crystal Devices for Adaptive Window Application. In Proceedings of Emerging Liquid Crystal Technologies V, San Francisco, CA, Jan 25-27 2010; Liang-Chy, C., Ed.; SPIE: Washington, DC, 2010; Vol. 7618, p 76180W. 
(23) You, X. Z.; Shan, B. Z.; Zhang, X. M.; Zheng, S. J.; Bai, Z. P.; Yang, J. X. Absorption Spectra of an Electrochromic Window Based on Molybdovanadophosphoric Acid, Prussian Blue and a Solid Polymer Electrolyte. J. Appl. Electrochem. 1997, 27, 1297-1299.

(24) Clear, R. D.; Inkarojrit, V.; Lee, E. S. Subject Responses to Electrochromic Windows. Energy Build. 2006, 38, 758-779.

(25) Kosc, T. Z. Motion of Polymer Cholesteric Liquid Crystal Flakes in an Electric Field. Ph.D. Dissertation, University of Rochester, Rochester, NY, 2003.

(26) Cox, G. P. Microencapsulation Effects on the Electro-Optical Behavior of Polymer Cholesteric Liquid Crystal Flakes. Ph.D. Dissertation, University of Rochester, Rochester, NY, 2009.

(27) Kosc, T. Z.; Marshall, K. L.; Jacobs, S. D.; Lambropoulos, J. C. Polymer Cholesteric Liquid-Crystal Flake Reorientation in an Alternating-Current Electric Field. J. Appl. Phys. 2005, 98, 013509.

(28) Imamura, K.; Yoshida, H.; Ozaki, M. Giant Light Deflection via Electro-Mechanical Modulation of Liquid Crystals. Appl. Phys. Lett. 2019, 114, 061901.

(29) De Vries, H. Rotatory Power and Other Optical Properties of Certain Liquid Crystals. Acta Crystallogr. 1951, 4, 219-226.

(30) Korenic, E. M.; Jacobs, S. D.; Fare, S. M.; Li, L. Cholesteric Liquid Crystal Flakes - A New Form of Domain. Mol. Cryst. Liq. Cryst. Sci. Technol., Sect. A 1998, 317, 197-219.

(31) Yoshida, H.; Nakazawa, G.; Tagashira, K.; Ozaki, M. SelfAlignment Behaviour of Photopolymerized Liquid Crystal MicroParticles in a Nematic Liquid Crystal. Soft Matter 2012, 8, 1132311327.

(32) Dierking, I.; Scalia, G.; Morales, P.; LeClere, D. Aligning and Reorienting Carbon Nanotubes with Nematic Liquid Crystals. Adv. Mater. 2004, 16, 865-869.

(33) Tie, W.; Bhattacharyya, S. S.; Lim, Y. J.; Lee, S. W.; Lee, T. H.; Lee, Y. H.; Lee, S. H. Dynamic Electro-Optic Response of Graphene/ Graphitic Flakes in Nematic Liquid Crystals. Opt. Express 2013, 21, 19867-19879.

(34) Tie, W.; Bhattacharyya, S.; Gao, Y.; Zheng, Z.; Shin, E.; Kim, T.; Kim, M.; Lee, J.; Lee, S. Dynamic Response of Graphitic Flakes in Nematic Liquid Crystals: Confinement and Host Effect. Nanomaterials $2017,7,250$.

(35) Imamura, K.; Yoshida, H.; Ozaki, M. Field Strength and Frequency Tunable, Two-Way Rotation of Liquid Crystal MicroParticles Dispersed in a Liquid Crystal Host. Soft Matter 2017, 13, 4433-4440.

(36) Trajkovska-Petkoska, A.; Varshneya, R.; Kosc, T. Z.; Marshall, K. L.; Jacobs, S. D. Enhanced Electro-Optic Behavior for Shaped Polymer Cholesteric Liquid-Crystal Flakes Made Using Soft Lithography. Adv. Funct. Mater. 2005, 15, 217-222.

\section{NOTE ADDED AFTER ASAP PUBLICATION}

This paper was published ASAP on October 17, 2019, with incorrect text in the footnote of Scheme 1. The corrected version was reposted on October 30, 2019. 